\title{
Modelling the effects of climate on long-term patterns of dissolved organic carbon concentrations in the surface waters of a boreal catchment
}

\author{
M. N. Futter ${ }^{1, *}$, M. Starr ${ }^{2}$, M. Forsius ${ }^{3}$, and M. Holmberg ${ }^{3}$ \\ ${ }^{1}$ Watershed Ecosystems Graduate Program, Trent University, Peterborough, K9J 7B8, Canada \\ ${ }^{2}$ Department of Forest Ecology, University of Helsinki, P.O. Box 27, 00014 Helsinki, Finland \\ ${ }^{3}$ Finnish Environment Institute, P.O. Box 140, 00251 Helsinki, Finland \\ *now at: Macaulay Land Use Research Institute, Craigiebuckler, AB15 8QH, UK
}

Received: 6 November 2006 - Published in Hydrol. Earth Syst. Sci. Discuss.: 11 September 2007

Revised: 26 November 2007 - Accepted: 5 February 2008 - Published: 5 March 2008

\begin{abstract}
Dissolved organic carbon concentrations ([DOC]) in surface waters are increasing in many regions of Europe and North America. These increases are likely driven by a combination of changing climate, recovery from acidification and change in severity of winter storms in coastal areas. INCA-C, a process-based model of climate effects on surface water [DOC], was used to explore the mechanisms by which changing climate controls seasonal to inter-annual patterns of $[\mathrm{DOC}]$ in the lake and outflow stream of a small Finnish catchment between 1990 and 2003. Both production in the catchment and mineralization in the lake controlled [DOC] in the lake. Concentrations in the catchment outflow were controlled by rates of DOC production in the surrounding organic soils. The INCA-C simulation results were compared to those obtained using artificial neural networks (ANN). In general, "black box" ANN models provide better fits to observed data but process-based models can identify the mechanism responsible for the observed pattern. A statistically significant increase was observed in both INCA-C modelled and measured annual average [DOC] in the lake. This suggests that some of the observed increase in surface water $[\mathrm{DOC}]$ is caused by climate-related processes operating in the lake and catchment. However, a full understanding of surface water [DOC] dynamics can only come from catchment-scale process-based models linking the effects of changing climate and deposition on aquatic and terrestrial environments.
\end{abstract}

Correspondence to: $\mathrm{M}$. N. Futter

(m.futter@macaulay.ac.uk)

\section{Introduction}

In recent years, dissolved organic carbon concentrations ([DOC]) in surface waters have increased across much of Europe and North America (Freeman et al., 2001, 2004; Worrall et al., 2004; Hongve et al., 2004; Evans et al., 2005; Skjelkvåle et al., 2005; Burns et al., 2006; Vuorenmaa et al., 2006). These increases have many consequences. Globally, the loss of terrestrial organic carbon to rivers is equivalent to $10 \%$ of the net ecosystem production on land (Schlesinger, 1991), and is thus an important part of the global carbon budget. Higher [DOC] in drinking water can be a human health issue. DOC reacts with the chlorine used in some drinking water treatment processes to produce potentially carcinogenic trihalomethanes (Chow et al., 2003). In some regions, where the main source of drinking water is surface water, the increase in DOC has crossed current water quality limits, resulting in increased costs for water treatment (Hongve et al., 2004). Most mercury ( $\mathrm{Hg}$ ), a potentially toxic metal, in the aquatic environment is associated with DOC (Ravichandran 2004). Increased surface water [DOC] may lead to higher fluxes of $\mathrm{Hg}$ and increased risk to humans and the environment. Organic material derived from terrestrial sources can play a major role in the food webs of humic lakes (Salonen et al., 1992). Changes in flux of DOC from the land to surface waters may alter the base of the aquatic food web and affect lake ecology. Rates of recovery from air pollution induced acidification will be affected by increasing [DOC] (Evans 2005; Wright et al., 2006). Increasing [DOC] in

Published by Copernicus Publications on behalf of the European Geosciences Union. 
soil waters will increase the rate of cation leaching, delaying the recovery of soils from acidification. However, the effect of increased leaching of cations from soils will hasten the rate of surface water recovery from acidification. Wright et al. (2006) argue that the manner in which climate change influences [DOC] in soil and surface waters is an important unknown in predicting the rates of ecosystem recovery from acidification.

Anthropogenic acidification, climate and land-use change all have the ability to alter surface water [DOC] through processes operating in the aquatic and terrestrial parts of the catchment. The relationship between recovery from anthropogenic acidification and increasing surface water $[D O C]$ is well-documented (Evans et al., 2005; Skjelkvåle et al., 2005; Vuorenmaa et al., 2006). Deposition of inorganic ions as a result of anthropogenic acidification or winter storms in coastal areas are a major control of [DOC]. Evans et al. (2005) have linked the long-term increase in surface water [DOC] in the UK to declines in acid deposition. Vuorenmaa et al. (2006) have observed a similar pattern in Finnish lakes. In coastal regions, winter storms can deposit large amounts of chloride, which is capable of depressing [DOC] in soils and surface waters. This effect has been shown experimentally by F. Moldan (personal communication) and through modelling of long-term time series (Futter and de Wit, 2008). Greater ionic strength as well as increased hydrogen ion and aluminium (Al) concentrations in soil solution all can decrease organic matter solubility (de Wit et al., 1999; Kalbitz et al., 2000).

Neff and Asner (2001) state that the two most important mechanisms controlling DOC flux from forested catchments are hydrologic flow paths and the sorption dynamics of organic carbon in soils. Catchment hydrology is controlled by climate. Sorption dynamics can be altered by climate effects on soil temperature and moisture (Christ and David, 1996). The majority of freshwater DOC is produced from the breakdown of plant and microbial material to form soil organic matter in the terrestrial part of the catchment (Lennon, 2004). Both biological and chemical processes control the fate of organic carbon in soils. If primary productivity increases as a result of increased atmospheric $\mathrm{CO}_{2}$ concentrations (Freeman et al., 2004) or microbial breakdown rates increase (Freeman et al., 2001), surface water [DOC] can be expected to rise.

Catchment DOC export is strongly related to land cover. Catchments with extensive areas of peat or wetlands typically export more DOC than upland forested catchments (Dillon and Molot, 1997; Kortelainen and Saukkonen, 1998). However, if the wetlands drain into lakes or standing water, much of the DOC can be lost to sedimentation or mineralization. Climate change is expected to alter surface water [DOC]. Inlake processes may lower surface water [DOC] while in-soil processes may cause them to increase. Schindler et al. (1997) showed that $[\mathrm{DOC}]$ in lakes decreased as a result of declining stream flow, and less input of organic carbon from the terres- trial environment. DOC may also be expected to decline as a result of greater mineralization and sedimentation associated with the longer water residence times that are caused by decreased flows. Worrall et al. (2004) suggest that warmer temperatures and increased drought severity can account for the observed increase in [DOC] in UK surface waters.

Once in surface waters, DOC can be lost through mineralization and sedimentation (Dillon and Molot, 1997). Mineralization is caused by microbial activity and photolytic processes (Vähätalo, 2000). Higher rates of photomineralization relative to microbial consumption have been reported in clear, acidic lakes (Gennings et al., 2001) than have been observed in humic lakes (Vähätalo, 2000).

Modelling is needed to constrain estimates of the rate of ecosystem recovery from the effects of acidification (Wright et al., 2006) and to forecast the effects of climate change on carbon cycling. Statistical models based on linear regression (Evans et al., 2005; Hongve et al., 2004), nonparametric trend tests (Worrall et al., 2004; Vuorenmaa et al., 2006), and artificial neural networks (ANN) (Clair et al., 1994, 1999; Holmberg et al., 2006) have been used to identify the deposition and climate-related drivers of changing surface water [DOC]. Process-based models have been developed to simulate parts of the carbon cycle in catchments. Liski et al. (2005) have developed a model of litter breakdown in forests, in-soil DOC dynamics have been modelled by Michalzik et al. (2003) and models of carbon evasion from lakes have been developed (Vähätalo and Wetzel, 2004). However, there are relatively few models capable of simulating the effects of climate and land-cover on catchment-scale [DOC] dynamics in soils and surface waters.

The aims to this paper are to simulate the effects of climate on long-term [DOC] in the surface waters of a boreal catchment and to compare the results of a process-based model to those obtained using an ANN.

\section{Materials and methods}

\subsection{Study site}

Valkea-Kotinen is a small headwater catchment situated within an extensive forested area in southern Finland (Ukonmaanaho et al., 1998). The catchment is located at $61^{\circ} 14^{\prime} \mathrm{N}$, $25^{\circ} 04^{\prime} \mathrm{E}$ (Fig. 1). Water chemistry is monitored in the lake and at the catchment outflow. Stream flow is monitored only at the catchment outflow. The catchment is in a protected conservation area and only receives background levels of long-range transported air pollution. The catchment has an area of 30 ha and the lake elevation is $156 \mathrm{~m}$ above sea level (a.s.l.). The long-term mean annual temperature in the area is $+3.1^{\circ} \mathrm{C}$ and the annual amount of precipitation is $618 \mathrm{~mm}$ of which approximately $30 \%$ falls as snow, giving rise to a distinct snowmelt peak in runoff at the end of April. Global 


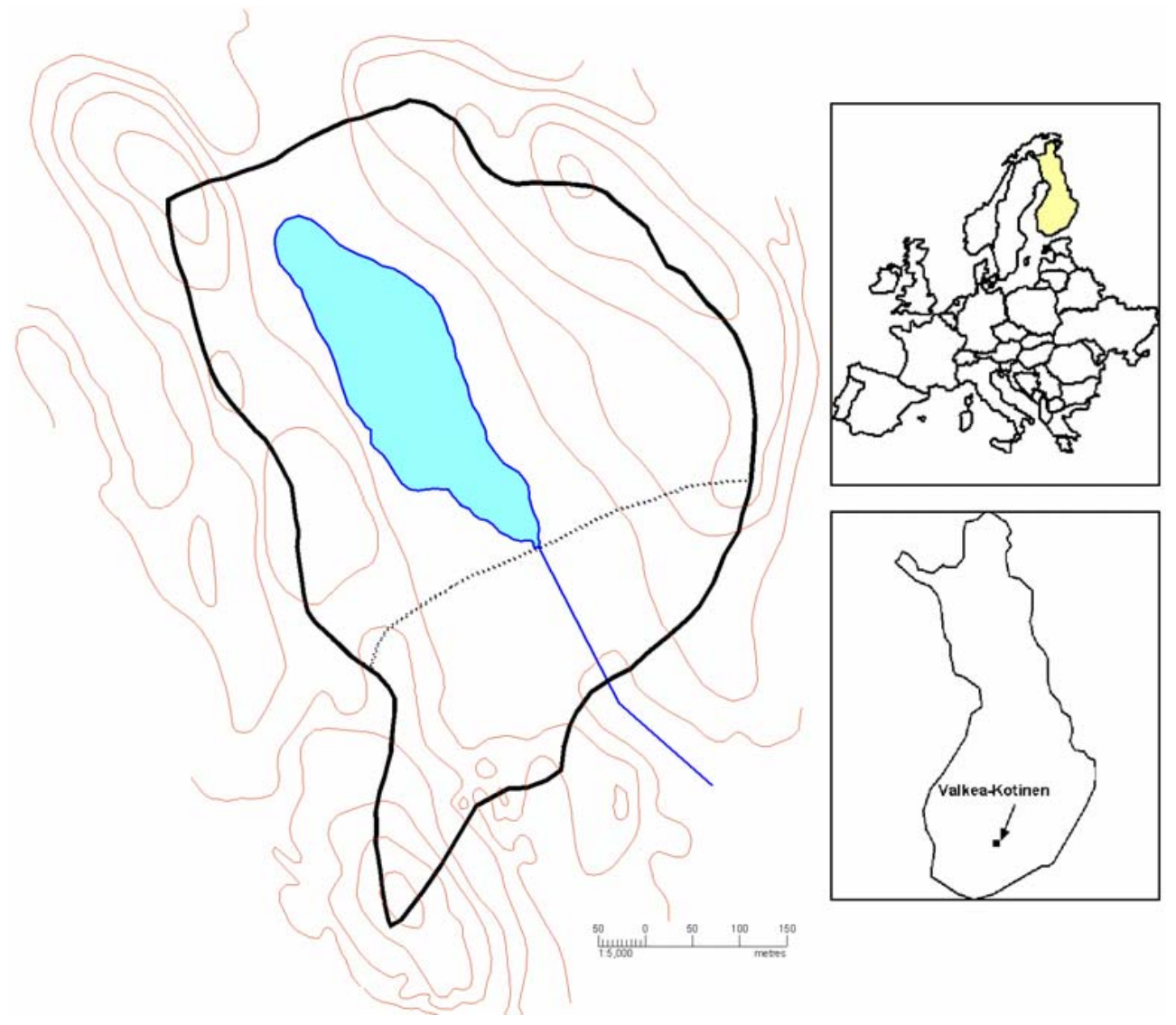

Fig. 1. Maps showing the Valkea-Kotinen catchment and its location in Europe. The dark solid line is the catchment boundary while the narrow dotted line represents the boundary between the sub-catchments. Water quality monitoring is conducted at both the lake outflow and the catchment outflow.

radiation averages $3300 \mathrm{MJ} \mathrm{m}^{-2} \mathrm{yr}^{-} 1$. Meteorological data used in this study were obtained from nearby Finnish meteorological institute weather stations. Temperature and precipitation data were obtained from the Lammi meteorological station $\left(61^{\circ} 10^{\prime} \mathrm{N} 25^{\circ} 02^{\prime}\right.$ E $129 \mathrm{~m}$ a.s.l.). Total global radiation data were obtained from Jokioinen $\left(60^{\circ} 48^{\prime} \mathrm{N}, 23^{\circ} 30^{\prime} \mathrm{E}\right.$, $104 \mathrm{~m}$ a.s.1.).

Valkea-Kotinen is typical of glaciated boreal landscapes. The catchment contains areas of forested mineral soil (17 ha, higher elevations), forested and open peatlands (7 ha, lower elevations and adjacent to the lake and stream) and a discharge lake (4 ha) with stream. The mineral soils in the catchments are predominately Podzols, developed on shallow glacial drift (till) deposits (Starr and Ukonmaanaho, 2001). The forest cover consists mainly of old-growth mixed stands of Norway spruce and deciduous species (birch and aspen) with large individuals of Scots pine present. The lake has a mean depth of $3 \mathrm{~m}$ and a volume of $7.7 \times 10^{4} \mathrm{~m}^{3}$ (Keskitalo et al., 1998). The lake drains through a stream flowing through a peatland. The water in the lake and the outlet stream are humic (average total organic carbon concentrations $=17 \mathrm{mg} \mathrm{L}^{-1}$ ), have low $\mathrm{pH}(4.5)$ and alkalinity $\left(-40 \mu \mathrm{mol} \mathrm{L}^{-1}\right)$. Further information about the catchment is available in Bergström et al. (1995).

The Valkea-Kotinen catchment has been the subject of much biogeochemical research (Forsius et al., 1995; Keskitalo et al., 1998; Starr and Ukonmaahano, 2001, 2004; Holmberg et al., 2006). The catchment is part of the UN/ECE ICP Integrated Monitoring program in Finland (http://unece. org/env/wge/im.htm). Because of this, detailed data on soil and stand carbon stocks, litterfall production and soil-water [DOC] are available (Starr and Ukonmaanaho, 2001, 2004). The lake has been the subject of numerous limnological studies, especially on greenhouse gas production (Vähätalo, 2000; Vähätalo et al., 2000, 2003).

\section{The INCA-C model}

\subsection{Model description}

INCA-C, the Integrated Catchments model for Carbon, is a dynamic, daily time-step, semi-distributed catchment scale process-based model of the effects of climate on DOC in 


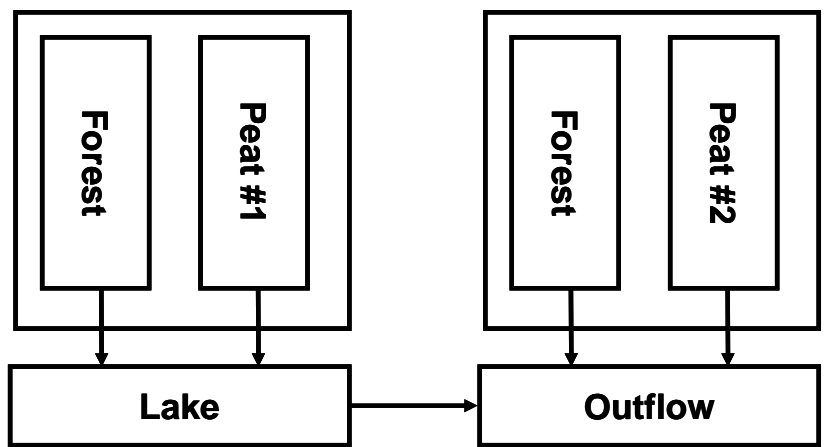

Fig. 2. Catchment structure used in modelling. The Valkea-Kotinen catchment was divided into two sub-catchments representing the lake and catchment outflow. Three land cover classes were used in the simulation. They represented (i) the forests in the lake and outflow sub-catchments, (ii) peat in the lake sub-catchment and (iii) peat in the catchment outflow.

surface waters (Futter et al., 2007). It is based on INCA$\mathrm{N}$ (Wade et al., 2002), which was developed to simulate nitrogen fluxes in European rivers. Because INCA-C is semidistributed, multiple sub-catchments can be modelled. When sufficient data are available on catchment land cover and soil properties, or if DOC and flow data are available at multiple points within the catchment, the overall catchment can be split and modelled as a series of sub-catchments (Fig. 2). Up to six different user-specified land-cover classes can be simulated in INCA-C. Within each land cover class, the soil is represented as a litter layer and two vertically stacked soil boxes. Water is routed directly from each land-cover class to surface water. There is no exchange of water or carbon between land-cover classes within a sub-catchment. In the application presented here, the catchment was divided into two subcatchments representing the lake at the top of the catchment and the peat lands and forest draining into the stream below the lake outflow (Fig. 1). Three land-cover classes were simulated representing (i) forests in both subcatchments, (ii) peatlands around the lake and (iii) the organic-rich soils and peat downstream of the lake outflow (Fig. 2).

Information on catchment area, sub-catchment boundaries, land cover within the catchment and soil properties are required to parameterize the model. Estimates of the volume of water in lakes or streams, the mass of solid organic carbon in the soil and [DOC] in soil water can be used to constrain the model parameter space. Time series of hydrologically effective rainfall (HER), soil moisture deficits (SMD) and air temperature are required to run INCA-C. Time series of stream flow and surface water [DOC] are used for model calibration.

Estimates of HER and SMD must be obtained from an external rainfall-runoff model. HBV (Salthun, 1996) was used for this purpose. HBV is a conceptual rainfall-runoff model that has been extensively used in Finland and Scandinavia. In
$\mathrm{HBV}$, time series of precipitation and temperature and a description of the catchment are used to simulate daily flows, HER and SMD. The model is calibrated by adjusting parameters so as to minimize the difference between modelled and observed flow. The estimate of HER generated by HBV is the depth of water that may enter the soil on any given day. For the purposes of this application, HER is defined as the sum of precipitation and snowmelt minus losses to evaporation and evapotranspiration. SMD is the difference between the amount of water in the soil and its water holding capacity, expressed as a depth of water. Stream flows estimated in HBV are only used for model calibration. They are not used in DOC simulations as INCA-C is able to route HER through the catchment and provide estimates of stream flow.

A detailed description of the INCA-C hydrology and carbon processing routines is presented by Futter et al. (2007). Briefly, the model simulates the following hydrological fluxes. Within a subcatchment, water arriving at the soil surface as a result of precipitation or snowmelt (HER) may flow directly to the surface water or percolate into the upper soil box. Water in the upper soil box may enter the stream through diffuse runoff or percolate to the lower soil box. All water in the lower soil box eventually runs off to the surface water. INCA-C does not simulate physical lake processes such as thermal stratification and evaporation. Evaporation can be a major component of a lake's water balance. The effects of evaporation on water balances and surface water outflows can be incorporated into INCA-C but must be estimated using an external model.

INCA-C simulates mass and flux of solid organic (SOC), dissolved organic (DOC) and dissolved inorganic carbon (DIC) in soils and surface waters. Breakdown of litter and root material contribute SOC and DOC to the upper soil box. Sorption and desorption processes transform organic carbon between DOC and SOC. Mineralization transforms SOC and DOC to DIC. DIC is lost to the atmosphere through degassing. DOC and DIC are transported advectively by water movement from the upper to lower soil boxes and from the soil to surface waters.

INCA-C models carbon transformations in soils and surface waters as a series of first-order processes. All in-soil rate coefficients are dependent on soil temperature and moisture status. Soil temperature was simulated using a model developed by Rankinen et al. (2004). The effect of soil temperature on the rate coefficients in INCA-C is simulated using a $\mathrm{Q}_{10}$ type model and the rate coefficient for the effect of soil moisture is a linear function of soil moisture content. The processes operate at a maximum rate when the simulated SMD is equal to zero. Processes cease when the SMD is greater than $\mathrm{SMD}_{\mathrm{Max}}$, a calibrated threshold representing the maximum soil moisture deficit at which carbon processing may occur. Equation (1) shows the effects of soil temperature $\left(T_{\text {Soil }}\right)$ and SMD on the change in mass of DOC in a soil box caused by sorption and desorption. The effect of soil temperature on the rate of carbon processing is simulated 
Table 1. "Soft" calibration parameters used in final round of model fitting. Published values and minimum and maximum values for acceptable soft calibrations as well as publication sources are presented.

\begin{tabular}{llllll}
\hline Parameter & Value & Min & Max & Units & Source \\
\hline Lake Volume & $7.70 \mathrm{E}+04$ & $7.00 \mathrm{E}+04$ & $8.50 \mathrm{E}+04$ & $\mathrm{~m}^{3}$ & Keskitalo et al. (1998) \\
Microbial Mineralization & 0.0065 & & & $\mathrm{~d}^{-1}$ & Vähätalo (2000) \\
Photolytic Mineralization & 0.0005 & 0.00045 & 0.00055 & $\mathrm{~d}^{-1}$ & Vähätalo (2000) \\
Peat Soil OC & 150 & 120 & 180 & $\mathrm{t} / \mathrm{ha}$ & Starr and Ukonmaanaho (2004) \\
Forest Soil OC & 80 & 65 & 100 & $\mathrm{t} / \mathrm{ha}$ & Starr and Ukonmaanaho (2004) \\
Upper Forest Soil DOC & 29.1 & 26 & 32 & $\mathrm{mg} / \mathrm{l}$ & Starr and Ukonmaanaho (2004) \\
\hline
\end{tabular}

using a calibrated $Q$ and modelled soil temperature $\left(T_{\text {Soil }}\right)$. The effects of soil moisture are simulated using daily values of SMD and a calibrated SMD $\mathrm{Max}$. The base rates of desorption $\left(k_{D}\right)$ and sorption $\left(k_{S}\right)$ are estimated during the calibration process.

$$
\begin{aligned}
& \frac{d \mathrm{DOC}}{d t}= \\
& Q^{\left(T_{\text {Soil }}-20\right)}\left(\frac{\mathrm{SMD}_{\mathrm{Max}}-\min \left(\mathrm{SMD}, \mathrm{SMD}_{\mathrm{Max}}\right)}{\mathrm{SMD}_{\mathrm{Max}}}\right)\left(k_{D} \mathrm{SOC}-k_{s} \mathrm{DOC}\right)
\end{aligned}
$$

DOC is lost from the open water through a combination of microbial and photo-mineralization. In open water, the DOC photo-mineralization rate is simulated as a function of incident solar radiation $(R)$ and surface water [DOC]. The photo-mineralization rate is a linear function of solar radiation. As high surface water [DOC] can lower rates of photo-mineralization, actual rates of photo-mineralization are calculated by multiplying the potential rate by a [DOC]dependent self-shading factor, $a /(a+[\mathrm{DOC}])$. Equation (2) shows the rate at which [DOC] changes in surface waters as a function of microbial $\left(k_{B}\right)$ and photolytic $\left(k_{P}\right)$ decay coefficients.

$$
\frac{d[\mathrm{DOC}]}{d t}=-\left(k_{B}+k_{P} R\left(\frac{a}{a+[\mathrm{DOC}]}\right)\right)[\mathrm{DOC}]
$$

\subsection{Model calibration}

Models were calibrated against hard and soft data (Seibert and McDonnell, 2002). Hard calibrations were conducted using a semi-automated strategy which adjusted parameter values so as to maximize the Nash-Sutcliffe (NS) statistic (Nash and Sutcliffe, 1970) of modelled and observed time series. The details of this method are provided by Futter et al. (2007). The NS statistic compares model predictions to those that would be obtained if the mean value of the observed time series were used as an alternate model of the data. Values of the NS statistic range between negative infinity and one. Values greater than zero indicate that the model provides a better fit to the data than simply fitting the mean. A value of one means the model provides a perfect fit.

Estimates of HER and SMD estimates were first obtained by calibrating HBV to observed stream flow at the catchment outflow. Model fit was assessed as the average of NS statistics from the raw and log-transformed data. This was done so as to capture the dynamics of high and low-flow periods.

The HER and SMD time series from the HBV calibration were used as fixed inputs to the INCA-C simulations. Observed time series of [DOC] at the lake and catchment outflow were used for hard calibration of INCA-C. Calibrations were first performed using the techniques described by Futter et al. (2007) to fit the modelled results to [DOC] in the lake. After a feasible parameter range had been found for predicting DOC in the lake, INCA-C was calibrated to [DOC] in both the lake and the catchment outflow.

Soft calibrations are qualitative estimates of model goodness of fit based on knowledge of the system being modelled (Seibert and McDonnell, 2002). Parameter values from the semi-automated hard calibration of INCA-C were adjusted so as to constrain model predictions to fall within the range of values in Table 1. Values for lake volume, soil organic carbon and soil [DOC] were obtained from Keskitalo et al. (1998) and Starr and Ukonmaanaho (2004). The values for microbial and photolytic mineralization were obtained from Vähätalo (2000). In a study of mineralization rates in Valkea-Kotinen conducted in the summer of 1994, he observed mineralization rates of $251 \mathrm{mg} \mathrm{C} \mathrm{m}^{-2} \mathrm{~d}^{-1}$ in the top $2 \mathrm{~m}$ of the lake. Assuming that only minimal rates of mineralization would occur below the epilimnion and that the lake has an average depth of $3 \mathrm{~m}$, approximately $84 \mathrm{mg} \mathrm{C} \mathrm{m}^{-3} \mathrm{~d}^{-1}$ were mineralized for the whole lake. During the summer of 1994 , measured [DOC] in the lake averaged $12 \mathrm{mgl}^{-1}$. Thus, DOC was mineralized at a rate of approximately $0.007 \mathrm{~d}^{-1}$. Vähätalo (2000) reported that $7 \%$ of the observed mineralization could be ascribed to the direct and indirect effects of solar radiation. Thus the rate of microbial mineralization could be fixed at $0.0065 \mathrm{~d}^{-1}$ and photolytic mineralization parameters in Eq. (2) constrained so as to ensure that the rate of photolytic mineralization ranged between 0.00045 and $0.00055 \mathrm{~d}^{-1}$. The parameter set that resulted in the highest NS statistic in the hard calibration of modelled to observed DOC was used as the starting point of a manual calibration that adjusted rate coefficients in the soil so as to satisfy the soft calibration criteria and preserve the pattern of simulated $[D O C]$ in the lake and catchment outflow. 


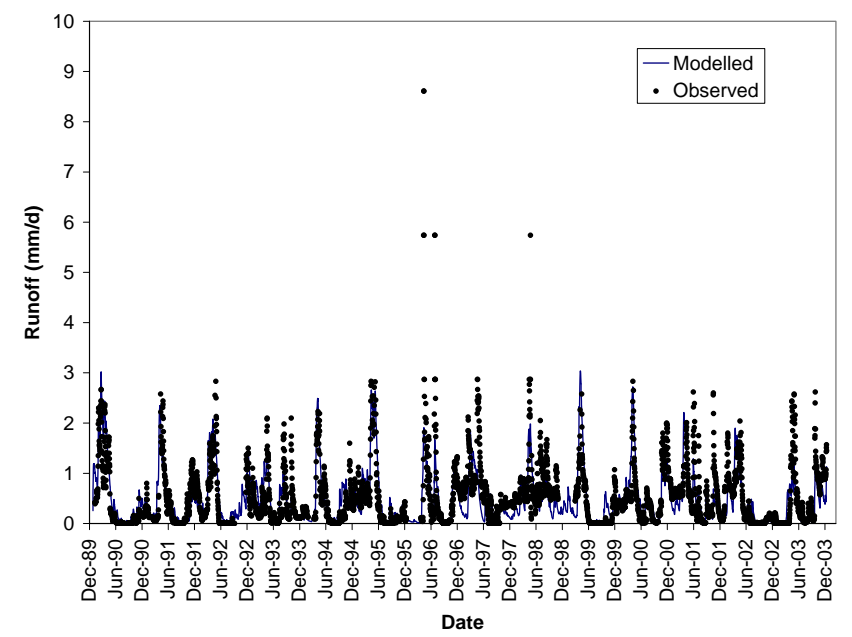

Fig. 3. Observed and HBV-modelled stream flow at the ValkeaKotinen catchment outflow.

\section{Results and discussion}

\subsection{Hydrological simulations}

The HBV stream flow simulation at Valkea-Kotinen was able to match the observed pattern of high and low flows at the catchment outflow (Fig. 3). The Nash-Sutcliffe statistics for fits of raw and log-transformed data were 0.55 and 0.53 , respectively. These statistics would be low if HBV were used for flood forecasting but are adequate for generating estimates of HER and SMD. HBV was unable to adequately simulate the very high-flow events in April and July of 1996 and May, 1998. The discrepancy between measured and modelled flows may be due to the distance between the weather station and the catchment. Local convectional storms may result in large amounts of precipitation falling on the catchment but not being observed at weather station and vice versa. Small catchments, such as Valkea-Kotinen, can be harder to model with HBV than catchments with areas in the 10$100 \mathrm{~km}^{2}$ range.

Estimates of SMD and HER from the HBV simulation were used as inputs to INCA-C. Initial INCA-C simulations of stream flow at the catchment outlet tended to over-estimate the flux of water leaving the catchment, especially during the summer months. The reason for these over-estimates is most likely because INCA-C does not model lake evaporation. Therefore, it over-estimates flow from the lake to the catchment outflow. This problem was most pronounced during summer months, when evaporation would be highest. To resolve this issue, lake evaporation was simulated using the coefficients from the HBV model run that had previously been used to estimate HER and SMD. A volume of water equal to the lesser of the simulated evaporation from the lake or modelled flow from the lake on that day was subtracted from the volume of water flowing through the lake outflow.
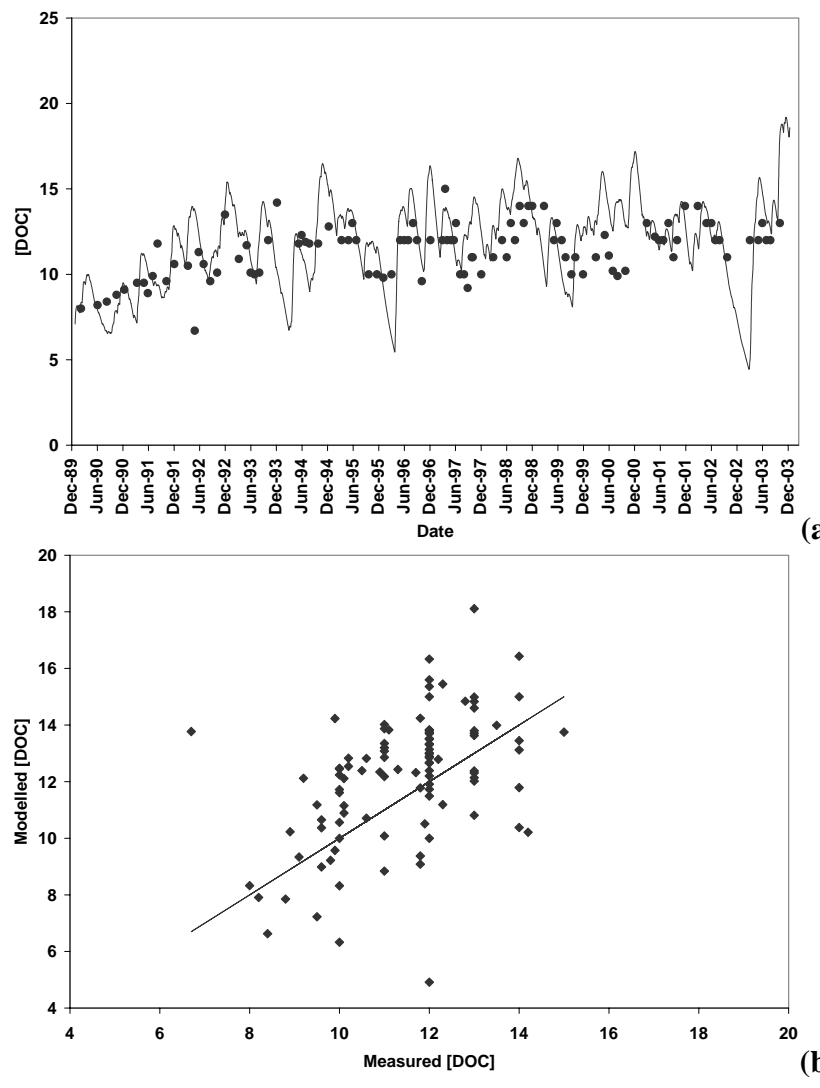

(a)

Fig. 4. (a) Observed and modelled [DOC] at the Valkea-Kotinen lake outflow. Dots represent observed values. (b) Scatter-plot of modelled versus measured [DOC] at the lake outflow.

\subsection{DOC simulations}

Time series of observed and modelled daily [DOC] in the lake and catchment outflow from 1990-2003 are shown in Figs. 4a and 5a. Scatter plots of modelled versus observed [DOC] are shown in Figs. $4 \mathrm{~b}$ and $5 \mathrm{~b}$. The parameter set used for generating estimates of [DOC] was derived from the soft calibration. This input to the soft calibration was derived from the best-performing parameter set from in excess of 30000 parameter sets that were created and evaluated during the course of hard simulation. During the hard simulation, it was not possible to obtain simulations with NS statistics $\geq 0.4$ for both sub-catchments simultaneously. The hard model calibrations where NS statistics were used to assess the correspondence between modelled and observed surface water [DOC] were complemented by "soft" calibrations where the parameter space was constrained to approximate measured catchment properties.

The model tended to under-predict [DOC] in the lake in the early 1990's and again in 1999-2000. It captured the seasonal pattern and mean values in the mid to late 1990's (Fig. 4a). The model captured the annual pattern of low 

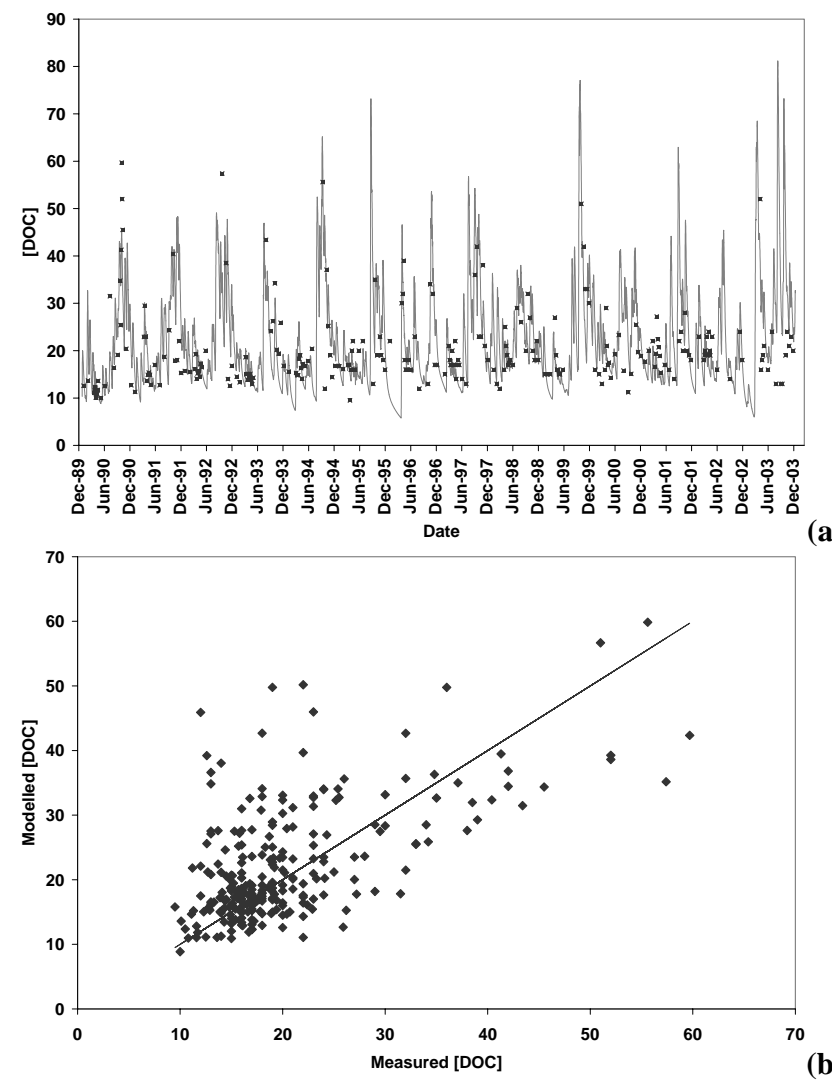

(a)

Fig. 5. (a) Observed and modelled [DOC] at the Valkea-Kotinen catchment outflow. Dots represent observed values. (b) Scatter-plot of observed and modelled [DOC] for the catchment outflow. The solid line is the $1: 1$ line.

spring and high autumn [DOC] in the catchment outflow. Peak [DOC] were over-estimated in 1995, 1999, 2001 and 2003 (Fig. 5a). The range of values from behavioural runs for any given day was greater for the catchment outflow predictions than for the lake. There were considerable differences between modelled and observed data (Figs. 4b and $5 b)$. While there was a monotonic relationship between modelled and observed, there was a considerable amount of unexplained variation.

The model was able to successfully reproduce the pattern in annual $[D O C]$ in the lake. It was less successful at simulating the inter-annual variability in [DOC] at the catchment outflow (Fig. 6). Mann-Kendall tests revealed a statistically significant increase in both modelled and observed [DOC] in the lake. No significant trends were observed in annual average values in either the measured or modelled time series from the catchment outflow.

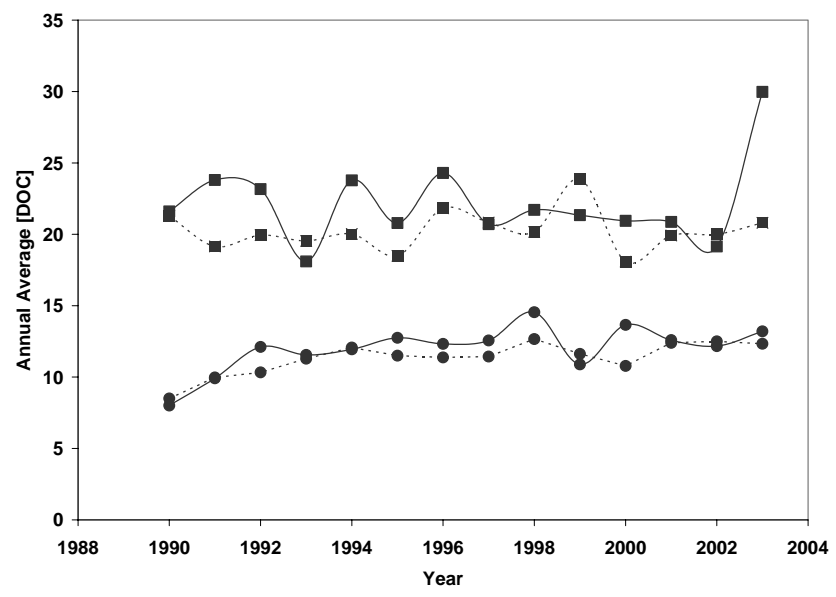

Fig. 6. Annual average measured (dashed lines) and modelled [DOC] (solid lines) in the lake (circles) and catchment outflow (squares). Annual averages are calculated using dates on which observations were made. Mann-Kendall statistics revealed a significant increase in observed and modelled [DOC] in the lake $(\mathrm{p}<0.01$, Sen slopes equal to 0.19 and $0.21 \mathrm{mg} \mathrm{DOC}^{-1} \mathrm{yr}^{-1}$ for the observed and modelled time series respectively).

\subsection{Discussion}

INCA-C was able to successfully simulate some of the seasonal variability and long-term dynamics in the lake and catchment outflow at Valkea-Kotinen. It is apparent, however, that factors other than those modelled here must have an influence on surface water [DOC].

Simulated [DOC] in the lake was sensitive to modelled rates of microbial mineralization and rates of DOC production in the catchment. In the catchment outflow, [DOC] was more sensitive to hydrologic flow-paths, water residence times, and rates of production in organic soils. The difference between the two sub-catchments may be largely a function of surface water residence time. Water is exposed to solar radiation for a much longer period of time in the lake than in the catchment outflow. If a changing climate results in decreased runoff and longer water residence times, aquatic processes will become more important in controlling surface water [DOC].

The results presented here are complementary to the findings of Vuorenmaa et al. (2006). In their study of thirteen lakes, including Valkea-Kotinen, they found statistically significant increases in total organic carbon concentrations in ten lakes between 1987-2003. They found that sulphate $\left(\mathrm{SO}_{4}\right)$ had declined and alkalinity increased in all thirteen lakes. While $\mathrm{pH}$ had shown statistically significant increases in seven of the thirteen lakes, the increase at Valkea-Kotinen $\left(0.001 \mathrm{pH}\right.$ units $\left.a^{-1}\right)$ was not significant. The increased $[D O C]$ in the lake was a result of INCA-C simulated increases in DOC production in the soil. It is also likely that the increased [DOC] has caused increased dissociation of 
organic acids in the lake water and thus slowed down the $\mathrm{pH}$ increase, expected based on the reduced acid deposition loads and observed increases in lake alkalinity concentrations.

Simulated $[\mathrm{DOC}]$ in the catchment outflow was more sensitive to the rate of DOC production and flow-paths in the surrounding peat soils than to mineralization in the stream. This is due in part to the much shorter residence time of water in the stream versus the lake. In the soil, DOC production was dependent on the effects of soil moisture and temperature. There may not have been much change in soil water pH between 1990 and 2003 as the catchment soil is acidified due to the high organic carbon content in the soil rather than anthropogenic deposition (Starr and Ukonmaahano, 2001). Model predictions of [DOC] in the catchment outflow were sensitive to water residence times in the soil and to simulated pore-space volumes. In-stream [DOC] was primarily a function of hydrology and rates of DOC production is in agreement with Neff and Asner's (2001) assertion that hydrology and organic carbon sorption dynamics are the main processes controlling DOC export from soils to surface waters.

\subsection{Comparison with artificial neural networks}

Ideally, different modelling approaches will lead to similar conclusions about the environmental forcing variable controlling surface water [DOC]. An artificial neural network (ANN) has been used to successfully simulate [DOC] at Valkea-Kotinen and Hietejärvi (Holmberg et al., 2006). In general, ANN models are simpler to apply than processbased models and often provide better fits of modelled to observed data. Process-based models such as INCA-C are complementary to "black-box" approaches like ANN. Application of an ANN can identify the environmental drivers which control [DOC] but cannot identify mechanism. Processbased models can identify mechanisms but care must be taken in their application to ensure all relevant processes are represented (Futter and de Wit, 2008). Comparisons of ANN and process-based model simulations have been published before (Lischeid and Langusch, 2004). However, they may not have adequately calibrated the process-based model. It is widely accepted that successful ANN simulations require a "training" or calibration period. Similarly, processbased models should be calibrated to local conditions. Failure to properly calibrate process-based models or to train ANN would invalidate the results of any ANN/process-based model comparisons. The calibrated INCA-C simulations presented here are suitable for comparison to ANN derived results.

The ANN model of Holmberg et al. (2006) used a suite of physiographic, temperature, and runoff-related parameters to predict DOC flux at two forested catchments in Finland. Deposition related processes were not considered.

Their model had a NS statistic of 0.728 and a correlation of 0.76 between modelled and measured data. Holmberg et al. (2006) found that catchment latitude, elevation and area, as well as the percentage of the catchment covered by peat soils or lakes all contributed to explaining [DOC]. Average daily temperatures over the past three and ten days were used to account for the effects of temperature on DOC flux. Their model incorporated an extensive suite of hydrological predictors. Runoff on the date of sampling was used as a predictor of DOC, as were the maximum and minimum runoff recorded over the previous three days. Time since peak flow and the number of days that the catchment had been in a period of low flow were also found to be important.

Like Holmberg et al. (2006), catchment physiography was found to be an important determinant of surface water [DOC]. Most of the DOC in the surface waters was produced in the peat soils in the catchment. Larger areas of open water lead to greater consumption of DOC. The flow related parameters in the ANN show the importance of discharge in predicting DOC flux. Soil and surface water hydrology are important in determining carbon fluxes in INCA-C. The importance of stream flow in both models supports Neff and Asner (2001) who state that hydrology is one of the key regulators of DOC loss from terrestrial systems. The average temperatures from the preceding three and ten days used in the ANN may be surrogates for soil temperature. The INCA$\mathrm{C}$ simulations suggest possible mechanisms for the manner in which the ANN-derived parameters influence surface water DOC. In-soil processes will occur more rapidly at warmer temperatures. If these warmer temperatures lead to drier conditions, process rates will be slower.

The ANN model was able to achieve higher NS statistics than the INCA-C simulations presented here. In some ways, this begs the question as to why one would use processbased models such as INCA-C when better statistical relationships between observed and predicted data can be obtained using empirical models such as ANN. Whenever there is enough information to calibrate a process-based model, such as INCA-C, the process-based model would be preferred over an empirical model based on ANN or other "black box" statistical methods. A process-based model is a mathematical formulation of the hypothesized mechanisms involved in triggering the system's response. Process based models can play two important roles. They allow for extrapolation into future conditions that are not represented in the observed set of events and they provide insight into the adequacy of current process understanding.

The Valkea-Kotinen catchment is well-suited to studies demonstrating the importance of aquatic and terrestrial processes on surface water [DOC]. The peat soils in the catchment produce large amounts of DOC. When DOC-rich water from the peat soil enters the lake, much of the DOC is lost through microbial mineralization. The relative importance of photolytic decay of DOC warrants further investigation. Less than $10 \%$ of the organic carbon mineralized at Valkea-Kotinen is consumed by the direct photomineralization (Vähätalo, 2000). The relative contribution 
of photomineralization may be much higher in clear, acidic lakes (Gennings et al., 2001). Less DOC is mineralized in water from the outflow stream than the lake due to its shorter residence time.

INCA-C was able to simulate the pattern of surface-water [DOC] in the Valkea-Kotinen catchment as a function of temperature and precipitation. This may be somewhat fortuitous. Valkea-Kotinen is recovering from acidification but the direct acidification-related effects on [DOC] may be secondary to climate. The $\mathrm{pH}$ of the lake is increasing but at an extremely low rate although the sulphate concentration is decreasing and alkalinity increasing (Vuorenmaa et al., 2006). Acid deposition is declining but the catchment is in an area of limited deposition, and surface waters are naturally acidic as a result of the large amounts of organic soil in the catchment. Less humic acid-sensitive Finnish lakes that have been subject to higher levels of acidic deposition in the past are currently displaying more rapid increases in $\mathrm{pH}$ (Vuorenmaa et al., 2006). In these lakes, the effects of declining acid deposition on the acidity status is more pronounced and it is expected that the INCA-C model which currently uses climate alone will not do as good a job in simulating trends at those sites.

The scatter-plots of modelled versus observed [DOC] in the lake and catchment outflow (Figs. $4 \mathrm{~b}$ and $5 \mathrm{~b}$ ) suggest that the direct influence of climate on the production and consumption of DOC in the catchment is limited; only explaining about $40 \%$ of the total variation in [DOC]. Better simulations could have been obtained if deposition processes were included in the model.

\subsection{Improvements to INCA-C}

Both the calibration method used here and INCA-C model structure could be improved. An automated calibration strategy that incorporated hard and soft calibration criteria would be desirable. INCA-C could be improved through incorporation of additional processes. Thermal stratification influences in-lake DOC processes. Salonen and Vähätalo (1994) noted that epilimnetic DOC was more resistant to photomineralization than DOC from hypolimnetic waters. They suggest that the amount of DOC in the epilimnions of stratified lakes that may potentially be mineralized is depleted over the summer. This occurs because DOC is consumed by photo-mineralization in the epilimnion more rapidly than it can be replaced through inflow from the catchment or through exchange with the hypolimnion. DOC is mineralized less rapidly in the hypolimnion as it is shaded by epilimnetic DOC.

Declines in acid deposition may have more of an effect on organic carbon sorption in catchment soils than climaterelated processes. Reductions in anthropogenic acid deposition should lead to lower ionic strength and decreased [Al] in soil-waters. Both of these factors should increase soil-water [DOC]. While both of these will lead to increased export of DOC from soils to surface waters, the actual mechanism and relative importance of ionic strength as opposed to Al-related is still unclear.

INCA-C is able to predict daily [DOC] on an annual to decadal time scale. Over longer time periods, changes in the mass of organic carbon in catchment soils will have an appreciable effect on surface water [DOC]. Integrating INCA-C with a carbon-sequestration model such as DyDOC (Michalzik et al., 2003) will reduce the uncertainty in longterm forecasts. Estimates of the effects of anthropogenic acid deposition on DOC dynamics in soils and surface waters would improve model predictions. More information on the controls of sorption/desorption dynamics of organic carbon in boreal soils would help in assessing the adequacy of the model of in-soil processes in INCA-C. Chloride, $\mathrm{SO}_{4}$ (Kalbitz et al., 2000) and Al (de Wit et al., 1999) can all influence organic carbon sorption dynamics in soils. Measured data on soil solution chemistry are available for some years but high quality modelled data would be useful as they would fill-in the time periods for which measured data were not available and would permit forecasting of future conditions.

Estimates of both terrestrial and aquatic $\mathrm{CO}_{2}$ effluxes would be useful for further constraining INCA-C calibrations. The INCA-C model could be improved if it were linked to a more detailed model of photochemical mineralization. Vähätalo et al. (2000) have developed a photochemical mineralization model derived from water samples collected at Valkea-Kotinen. Running this model would provide independent validation of the INCA-C estimates. This would also provide a more complete accounting of carbon fluxes in the catchment (Starr et al., 2005), as it would provide an estimate of the $\mathrm{CO}_{2}$ efflux to the atmosphere from the lake. Recently started $\mathrm{CO}_{2}$ efflux measurements at the lake, using eddy-covariance techniques, would also provide additional data for model validation. The decomposition rates of soil organic matter at Valkea-Kotinen has been studied using the weight loss of cellulose strips placed on and in the surface organic layer (Kurka et al., 2000), but direct measurements of soil $\mathrm{CO}_{2}$ effluxes to the atmosphere have not been made. Estimates of terrestrial $\mathrm{CO}_{2}$ effluxes would be very helpful to constrain the INCA-C parameter space, as they could provide more realistic estimates of rates of carbon sequestration and loss. It is possible to derive such estimates using soil organic matter decomposition models such as YASSO (Liski et al., 2005).

\section{Conclusions}

While both deposition and climate control surface water [DOC], the INCA-C model is able to simulate some of the seasonal dynamics and long-term trends in $[\mathrm{DOC}]$ in the lake and outflow of a boreal catchment containing both upland forest and peat soils. The INCA-C model results suggested climate-related processes that linked the external drivers identified earlier using an ANN model to observed 
surface water $[\mathrm{DOC}]$. In catchments with lakes or other extensive areas of standing water, both in-soil production and in-lake mineralization of control surface water [DOC]. In stream-dominated catchments, annual patterns of stream flow and the rates of DOC production in organic soils are the dominant processes. However, the model fit indicated that processes other than climate play a major role in controlling surface water [DOC]. The utility of the model will be greatly enhanced through incorporation of the depositionrelated mechanisms that are hypothesized to control DOC in soils and surface waters. Simulating the effects of acid deposition will require a better understanding of whether the mechanism by which $\mathrm{SO}_{4}$ controls [DOC] in soils is related to ionic strength, $\mathrm{Al}$, or some other factor. Simulating lake evaporation and thermal stratification would make the model mode widely applicable. More realistic estimates of $\mathrm{CO}_{2}$ efflux would improve the quality of predictions.

An ability to model soil and surface water DOC will be vital in assessing the impact of changes in organic acidity on the rate of recovery from acidification (Wright et al., 2006). Future work with INCA-C at Valkea-Kotinen is planned and will evaluate the projected effects of climate change and reductions in anthropogenic acid deposition on [DOC] and how changing $[\mathrm{DOC}]$ may affect the chemistry of acidification in boreal surface waters.

Acknowledgements. The comments of two anonymous reviewers greatly improved the manuscript. The manuscript benefited from discussions with P. Kortelainen and L. Arvola and editing advice from H. Evans. The data for this project were provided by the Finnish Meteorological Institute, Finnish Forest Research Institute and Finnish Environment Institute as part of the UNECE ICP Integrated Monitoring Programme and funded and supported by the Ministry of the Environment and the Ministry of Agriculture and Forestry. This study was carried out as part of the Commission of European Communities project EUROLIMPACS (Integrated project to evaluate impacts of global change on European freshwaters ecosystems, GOCE-CT-2003-505540, http://www.eurolimpacs.ucl.ac.uk). The ANN modelling was funded by the CNTER-project (QLK5-2001-00596, EC) and the Academy of Finland. A Canadian NSERC IPS fellowship supported M. N. Futter.

Edited by: P. Dillon and R. F. Wright

\section{References}

Bergström, I., Mäkelä, K., and Starr, M. (Eds.): Integrated Monitoring Programme in Finland, First National Report, Ministry of the Environment, Environmental Policy Department, Report 1. 1995, Ministry of the Environment, p. 138 (+7 appendices), 1995.

Burns, D. A., McHale, M. R., Driscoll, C. T., and Roy, K. M.: Response of surface water chemistry to reduced levels of acid precipitation: comparison of trends in two regions of New York, USA, Hydrol. Processes, 20, 1611-1627, 2006.
Chow, A. T., Tanji, K. K., and Gao, S.: Production of dissolved organic carbon (DOC) and trihalomethane precursor (THM) from peat soils, Water Res., 37, 4475-4485, 2003.

Christ, M. J. and David, M. B.: Temperature and moisture effects on the production of dissolved organic carbon in a spodosol, Soil Biol. Biochem., 28, 1191-1199, 1996.

Clair, T. A., Pollock, T. L., and Ehrman, J. M.: Exports of carbon and nitrogen from river basins in Canada's Atlantic provinces, Global Biogeochem. Cy., 8, 441-450, 1994.

Clair, T. A., Ehrman, J. M., and Higuchi, K.: Changes in freshwater carbon exports from Canadian terrestrial basins to lake and estuaries under a $2 \mathrm{XCO}_{2}$ atmospheric scenario, Global Biogeochem. Cy., 13, 1091-1097, 1999.

De Wit, H. A., Kotowski, M., and Mulder, J.: Modeling aluminum and organic matter solubility in the forest floor using WHAM, Soil Sci. Soc. Am. J., 63, 1141-1148, 1999.

Dillon, P. J. and Molot, L.: Dissolved organic and inorganic carbon mass-balances in central Ontario lakes, Biogeochemistry, 36, 2942, 1997.

Evans, C. D.: Modelling the effects of climate change on an acidic upland stream, Biogeochemistry, 74, 21-46, 2005.

Evans, C. D., Monteith, D. T., and Cooper, D. M.: Long-term increases in surface water dissolved organic carbon: Observations, possible causes and environmental impacts, Environ. Pollut., 137, 55-71, 2005.

Freeman, C., Ostle, N., and Kang, H.: An enzymatic 'latch' on a global carbon store, Nature, 409, p. 149, 2001.

Freeman, C., Fenner, N., Ostle, N. J., Kang, H., Dowrick, D. J., Reynolds, B., Lock, M. A., Sleep, D., Hughes, S., and Hudson, J.: Export of dissolved organic carbon from peatlands under elevated carbon dioxide levels, Nature, 430, 195-198, 2004.

Forsius, M., Kleemola, S., Starr, M., and Ruoho-Airola, T.: Ion mass budgets for small forested catchments in Finland, Water Air Soil Poll., 79, 19-38, 1995.

Futter, M. N., Butterfield, D., Cosby, B. J., Dillon, P. J., Wade, A. J., and Whitehead, P. G.: Modeling the mechanisms that control in-stream dissolved organic carbon dynamics in upland and forested catchments, Water Resour. Res., 43, W02424, doi:10.1029/2006WR004960, 2007.

Futter, M. N. and de Wit, H.: What controls dissolved organic carbon concentrations in streams: a comparison of empirical and process-based models, Sci. Total Environ., in press, 2008.

Gennings, C., Molot, L. A., and Dillon, P. J.: Enhanced photochemical loss of organic carbon in acidic waters, Biogeochemistry, 52, 339-354, 2001.

Holmberg, M., Forsius, M., Starr, M., and Huttunen, M.: An application of artificial neural networks to carbon, nitrogen and phosphorus concentrations in three boreal streams and impacts of climate change, Ecol. Modell., 195, 51-60, 2006.

Hongve, D., Riise, G., and Kristiansen, J. F.: Increased colour and organic acid concentrations in Norwegian forest lakes and drinking water: a result of increased precipitation?, Aquatic Sci., 66, 231-238, 2004.

Kalbitz, K., Solinger, S., Park, J.-H., Michalzik, B., and Matzner, E.: Controls on the dynamics of dissolved organic matter in soils: A review, Soil Sci., 165, 277-304, 2000.

Keskitalo, J., Salonen, K., and Holopainen, A.-L.: Long-term fluctuations in environmental conditions, plankton and macrophytes in a humic lake, Valkea-Kotinen, Bor. Environ. Res., 3, 251-262, 
1998.

Kortelainen, P. and Saukkonen, S.: Leaching of nutrients, organic carbon and iron from Finnish forestry land, Water Air Soil Poll., 105, 239-250, 1998.

Kurka, A.-M., Starr, M., Heikinheimo, M., and Salkinoja-Salonen, M.: Decomposition of cellulose strips in relation to climate, litterfall nitrogen, phosphorus and $\mathrm{C} / \mathrm{N}$ ratio in natural boreal forests, Plant. Soil, 219, 91-101, 2000.

Lennon, J. T.: Experimental evidence that terrestrial carbon subsidies increase $\mathrm{CO}_{2}$ flux from lake ecosystems, Oecologia, 138, 584-591, 2004.

Lischeid, G. and Langusch, J.: Comparative simulation of the nitrogen dynamics using the INCA model and a neural network analysis: implications for improved nitrogen modelling, Hydrol. Earth Syst. Sci., 8, 742-750, 2004, http://www.hydrol-earth-syst-sci.net/8/742/2004/.

Liski, J., Palosuo, T., Peltoniemi, M., and Sievänen, R.: Carbon and decomposition model Yasso for forest soils, Ecol. Modell., 189, 168-182, 2005.

Michalzik, B., Tipping, E., Mulder, J., Gallardo Lancho, J. F., Matzner, E., Bryant, C. L., Clarke, N., Lofts, S., and Vincente Esteban, M. A.: Modelling the production and transport of dissolved organic carbon in forest soils, Biogeochemistry, 66, 241264, 2003.

Nash, J. E. and Sutcliffe, J. V.: River flow forecasting through conceptual models Part I - a discussion of principles, J. Hydrol., 10, 282-290, 1970.

Neff, J. C. and Asner, G. P.: Dissolved organic carbon in terrestrial systems: synthesis and a model, Ecosystems, 4, 29-48, 2001.

Rankinen, K., Karvonen, T., and Butterfield, D.: A simple model for predicting soil temperature in snow-covered and seasonally frozen soil: model description and testing, Hydrol. Earth Syst. Sci., 8, 706-716, 2004, http://www.hydrol-earth-syst-sci.net/8/706/2004/.

Ravichandran, M.: Interactions between mercury and dissolved organic matter - a review, Chemosphere, 55, 319-331, 2004.

Salonen, K., Arvola, L., Tulonen, T., Hammar, T., Metsälä, T.-R., Kankaala, P., and Münster, U.: Planktonic food chains of a highly humic lake. I. A mesocosm experiment during the spring primary production maximum, Hydrobiologia, 229, 125-142, 1992.

Salonen, K. and Vähätalo, A.: Photochemical mineralisation of dissolved organic matter in lake Skjervatjern, Environ. Int., 20, 307312, 1994.

Salthun, N. R.: The "Nordic" HBV Model. Description and documentation of the model version developed for the project Climate Change and Energy Production, NVE Publication 7, Norwegian Water Resources and Energy Administration, Oslo, 26 pp., 1996.

Schindler, D. W., Curtis, P. J., Bayley, S. E., Parker, B. R., Beaty, K. G., and Stainton, M. P.: Climate-induced changes in the dissolved organic carbon budgets of boreal lakes, Biogeochemistry, 36, 9-28, 1997.

Schlesinger, W. H.: Biogeochemistry: an analysis of global change, Academic Press, 1991.

Seibert, J. and McDonnell, J. J.: On the dialog between modeler and experimentalist in catchment hydrology: use of soft data for multi-criteria model calibration, Water Resour. Res., 38, 1241, doi:10.1029/2001WR000978, 2002.

Skjelkvåle, B. L., Stoddard, J. L., Jeffries, D. S., Tørseth, K., Hogasen, T., Bowman, J., Mannio, J., Monteith, D. T., Mosello,
R., Rogora, M., Rzychon, D., Vesely, J., Wieting, J., Wilander, A., and Worsztynowicz, A.: Regional scale evidence for improvements in surface water chemistry 1990-2001, Environ. Pollut., 137, 165-176, 2005.

Starr, M. and Ukonmaanaho, L.: Levels and characteristics of TOC in throughfall, forest floor leachate and soil solution in undisturbed boreal forest ecosystems, Water Air Soil Poll. Focus, 4, 715-729, 2004.

Starr, M. and Ukonmaanaho, L.: Results from the first round of the integrated monitoring soil chemistry subprogramme, in: Forest Condition in Finland, edited by: Ukonmaanaho, L. and Raitio, H., National Report 2000, Finnish Forest Research Institute, Helsinki, Research Papers 824, 140-157, 2001.

Starr, M., Vanhala, P., and Forsius, M.: Progress report on calculation of carbon and nitrogen budgets for Finnish ICP IM catchments, in: 14th Annual Report 2005, edited by: Kleemola, S. and Forsius, M., UN ECE ICP Integrated Monitoring, Finnish Environment Institute, Helsinki, Finland, The Finnish Environment, 788, 44-49, 2005.

Ukonmaanaho, L., Starr, M., and Ruoho-Airola, T.: Trends in sulphate, base cations and $\mathrm{H}^{+}$concentrations in bulk precipitation and throuhgfall at integrated monitoring sites in Finland 19891995, Water Air Soil Poll., 105, 353-363, 1998.

Vähätalo, A. V.: Role of photochemical reactions in the biogeochemical cycling of detrital carbon in aquatic ecosystems, Academic Dissertation in Microbiology, University of Helsinki, Finland, 2000 .

Vähätalo, A. V. and Wetzel, R. G.: Photochemical and microbial decomposition of chromophoric dissolved organic matter during long (months - years) exposure, Mar. Chem., 89, 313-326, 2004.

Vähätalo, A. V., Salonen, K., Münster, U., Järvinen, M., and Wetzel, R. G.: Photochemical transformation of allochthonous organic matter provides bioavailable nutrients in a humic lake Arch, Hydrobiol., 156, 287-314, 2003.

Vähätalo, A. V., Salkinoja-Salonen, M., Taalas, P., and Salonen, K.: Spectrum of the quantum yield for photochemical mineralization of dissolved organic carbon in a humic lake, Limnol. Oceanogr., 45, 664-676, 2000.

Vuorenmaa, J., Forsius, M., and Mannio, J.: Increasing trends of total organic carbon concentrations in small forest lakes in Finland from 1987 to 2003, Sci. Total Environ., 365, 47-65, 2006.

Wade, A. J., Durand, P., Beaujouan, V., Wessel, W. W., Raat, K. J., Whitehead, P. G., Butterfield, D., Rankinen, K., and Lepistö, A.: A nitrogen model for European catchments: INCA, new model structure and equations, Hydrol. Earth Syst. Sci., 6, 559-582, 2002,

http://www.hydrol-earth-syst-sci.net/6/559/2002/.

Wright, R. F., Aherne, J., Bishop, K., Camarero, L., Cosby, B. J., Erlandsson, M., Evans, C. D., Forsius, M., Hardekopf, D. W., Helliwell, R., Hruska, J., Jenkins, A., Kopáček, J., Moldan, F., Posch, M., and Rogora, M.: Modelling the effect of climate change on recovery of acidified freshwaters: relative sensitivity of individual processes in the MAGIC model, Sci. Total Environ., 365, 154-166, 2006.

Worrall, F., Harriman, R., Evans, C. D., Watts, C. D., Adamson, J., Neal, C., Tipping, E., Burt, T., Grieve, I., Monteith, D., Naden, P. S., Nisbet, T., Reynolds, B., and Stevens, P.: Review of riverine DOC trends in the UK, Biogeochemistry, 70, 369-402, 2004. 